УДК 621.3.052.63

\title{
PHENOMENON OF COMPLEX SYSTEMS - A MATTER FOR SCIENTIFIC ENQUIRY
}

\section{DOI 10.36994/2707-4110-2020-1-28-11}

Ishchenko A. V., Scientific-scientific complex "Institute of Applied System Analysis NNK IPSA", National Technical University of Ukraine, "Kiev Polytechnic Institute of Im. Igor Sikorskiy@gmail.com"

Rogoza V. S., Dr. habil., Prof., Scientific-Scientific Complex "Institute of Applied System Analysis - NNK IPSA", National Technical University of Ukraine, "Kiev Polytechnic Institute of the Institute of Correspondence"; rosvetnik@gmail.com

Abstract. Complex systems is the subject of some mathematical studies in a series of fundamental and applied scientific areas. At present complex systems become the subject of interdisciplinary study and the increasing attention of researchers who seek more effective solutions of "traditional" tasks as well as develop generalized theories and methods which offer a clearer view of new problems that come under the heading of stubborn problems. The paper discusses the phenomenon of complex systems in the form of retrospective historical analysis and is aimed at promoting a better understanding of the mentioned phenomenon as a problem of mathematical and computer simulation.

Keywords: complex systems, mathematical and computer simulation, computer science technologies.

\section{ФЕНОМЕН СКЛАДНИХ СИСТЕМ - СПРАВА ДЛЯ НАУКОВОГО ДОСЛІДЖЕННЯ}

\begin{abstract}
Іщенко А. В., Навчально-науковий комплекс "Інститут Прикладного Системного Аналізу - ННК ІПСА", Національний Технічний Університет України, "Київський політехнічний інститут ім. Ігоря Сікорського", annvalish@gmail.com

Рогоза В. С., д.т.н., проф., Навчально-науковий комплекс "Інститут Прикладного Системного Аналізу - ННК ІПСА", Національний Технічний Університет України, "Київський політехнічний інститут ім. Ігоря Сікорського"; rosvetnik@gmail.com
\end{abstract}

Анотація. Складні системи є предметом математичних досліджень у ряді фунндаментальних та прикладних наукових областей. В даний час складні системи стають предметом міждисциплінарних досліджень та зростаючої уваги дослідників, які шукають більш ефрективних рішень «традиційних» завдань, а також розробляють узагальнені теорії та методи, які дають більш чітке уявлення про нові проблеми, що стають головним напрямом наукових досліджень останнім часом. У статmі розәлядається явище складності систем (як міждисциплінарний

(C) Іщенко А. В., Рогоза В. С.

(C) Вісник Унівеситету «Україна», № 1 (24), 2020 
напрямок досліджень) у фоормі ретроспективного історичного аналізу, що сприяє кращому розумінню цього френомену як проблеми математичного та комп'ютерного моделювання.

Ключові слова: складні системи, математичне та комп'ютерне моделювання, інформаційні технології.

\section{Introduction}

The "complex" word means in a literal sense that a given problem is too difficult to be solved, simulated or analyzed by "conventional" methods. Different scientific disciplines study in one way or another structural and functional properties of complex systems and the complexity phenomenon as a whole. Researchers are dealing with complex objects and systems in such scientific fields as: modern system theory (the certainty theory, automata theory), chemistry (simulation of chemical kinetics processes, organic synthesis), physics (theory of phase transitions, theory of dissipative structures), cybernetics (robotics), economy (system research, game theory), sociology (models of people migration and nation development), biology (research of DNA, genetic engineering), and so on.

Each scientific area has its own facilities for the analysis of complex objects, own terminology and investigation subject enriching our image and knowledge on this topic. Among the modern scientific areas, computer simulation fills a particular place, since it operates with abstract mathematical and computer models which are irrespective of the physical origin of objects to be simulated. Therefore, the whys and wherefores of morphologic and functional properties of complex objects (systems, processes) can be considered as a topic, which is actual in the theory of mathematical and computer simulation due to the fact that it provides some common-used facilities for simulation complex objects in categories of formal models and generalized principles.

But where is the threshold that resolves "inconvenient" complex systems from those, whose behavior is well within the permissible limits of existing models and well-known simulation methods?

As is a well-known fact that biology dealing with the natural complex objects, has suggested the concept of complexity in anthropological categories, which were extended to the area of artificial intelligent and the general system theory. Say, the theory of artificial intelligence considers complexity as the capability of a system to self-organization and adaptive behavior in the varying environment (Russel and Norvig, 2003). If the system is capable of adapting its behavior through learning and in such a way it optimizes its actions, such a system is usually called the intelligent system. It is particularly remarkable that adaptation as a key property of any highlyorganized system is shared by both natural and artificial objects. This fact was observed early in the development of the theory of intelligent systems (e.g., see (Wiener, 1948; Ashby, 1960) as well as in subsequent investigations (e.g., see Holland, 1992).

Be it as it may, but belief has grown up historically that behavioral complexity of a system arises from its intelligence, and conversely - any intelligent system is 
complex. The animal's or human's brain offers a natural specimen of a universal intelligent system in nature. Therefore the brain is an inexhaustible source for investigations and the object that induces our effort to search for the origin

in the natural intelligence and to form our concepts on the fundamental mechanisms of building artificial intelligent systems. The brain is interesting for the researchers not only as an object endowed by an extraordinarily complexity, but also as a natural supercomputer, which is capable of solving sophisticated tasks through self-organizing learning and adaptation and tuning optimal algorithms allowing solution of ill-formalized problems. Much has been made in the field of building intelligent machines allowing effective solution of the mentioned problems, but nevertheless it should be noted that properties of complex systems (objects, processes), whose computer simulation requires invoking intelligent facilities, have not been adequately explored yet.

In this context, the question arises is it possible to classify problems into the two categories: the problems which could be solved successfully using conventional approaches, and those which require the use of intelligent computing machines? One can foresee a cry of astonishment: the classical theory of computation provides the response to this question, don't it? Indeed, the theory gives us a good indication of problems that can be solved using, say, Turing's machines, and moreover, it determines what problems come under the heading of unresolvable or hardresolvable (Hopcroft et al., 2001). But unfortunately, we know a little on the nature of the complexity phenomenon in general. This question is likely of fundamental importance in the development of methods of simulation of complex systems.

In this article, we would like to initiate interest to this topic among the researchers, whose professional interests are involved into the area of computer simulation of complex objects of different nature. First, we shall make a retrospective journey into the history of complex system investigations allowing better understanding of the role of this topic in the development of computer science, and

then we would like to discuss some modern specific problems issuing from this extensive scientific problem.

Taking into account the verbal character of the article and for the convenience of the Reader, the authors have arranged references to literature in alphabetical order according to the authors' names.

\section{Backward glance at the advancement of notions of complex objects}

It has long been known that mathematical objects might be complex not only in consequence of a large set of equations which describe the behavior of any object and not only of ill-conditioning the model used, but in consequence of sophisticated behavior of objects that we intend to analyze using computer facilities. The living objects that we can observe in Nature place at our disposal examples of systems of that kind. There are some characteristic features of natural complex objects listed in biology:

Feature 1. The capacity for development, self-organization, and adaptation. 
Feature 2. The survival of the fittest caused by the adaptation property.

Feature 3. Inter-individual co-adaptation (that is, group adaptation, as it is called).

Feature 4. Information exchange between the individuals.

Feature 5. Hierarchical organization of adaptive mechanisms.

Borrowing the concepts of complex objects from the living Nature suggests many researchers to the conclusion that complexity is a fundamental property of any intelligent object, be it a natural or artificial object. From the above reasoning, researchers had come to the point of view that the complexity phenomenon can be interpreted in anthropological categories, although such an analogy

is sometimes deluded on occasion. As was noted above, characteristics of natural objects, such as self-organization and adaptation are key words that characterize highly organized systems in Nature. Nevertheless, the anthropological point of view was not a single concept of the complexity phenomenon. As to computer science, the problem of investigation of complex objects was historically associated with the problem of the development of a universal algebraic concept (measure) of computability of math models using a universal computing machine. This idea dates back to the investigations of Alan Turing, whose research since 1930s was devoted to the development of the theory of an abstract computing machine (Turing's machine, as it was called). The subject of his research was to establish which functions can be principally calculated using formal logics.

A closer look at the given problem shows that it also broaches one of fundamental mathematical problems formulated by David Hilbert at the International Mathematical Conference in Paris in 1900. The problem (known as the problem of finding solution in the closed formal logic system, or Entscheidungsproblem) might be interpreted as follows: are there properties of math objects, which constrain power of effective procedures of theorem proving in an arbitrary closed formal logic system?

If they are, then a minimal program code size and minimal set of input data required to solve the problem of a given class might be considered as certain measures of problem complexity.

In 1930, Kurt Gödel showed that there is an effective procedure of proving any true statement in the first order Frege and Russel logics, but at the same time the first order logics possesses some fundamental restrictions, namely it does not allow for using the math induction principle to prove math theorems. But a crippling blow upon the idea of finding universal basis of theorem proving was struck by Gödel in 1931, when he published the fundamental theorem on the incompleteness of any logic system, namely: in any logic system, there is a statement whose truth or false cannot be proved within the bounds of the given logic system (Gödel, 1931).

Perhaps, in response to the mentioned fundamental results, A. Turing has discovered that there are classes of functions, which cannot be calculated using "universal" Turing's machine, and the power of the universal machine was constrained by the Chirch-Turing thesis: Turing's machine is that one, which is 
capable of calculating any computable function. The classes of incomputable functions

were naturally fallen to the category of complex math objects. Among other things, it means that there is not a universal method, which makes it possible to determine the fact that a given problem can be solved by a computer program within a terminal time.

More recently, A. Cobham and J.Edmonds (Cobham, 1964; Edmonds, 1965) showed that there are a great body of math problems, whose time solution grows exponentially with the increase of the number of variables. Based on this study, they introduced the concept of NP-difficult problems into the theory of calculation, and S.A.Cook and R.M. Karp (Cook, 1971; Karp, 1971) proved that NP-difficult problems represent a broad class of canonical problems of information retrieval. But in general the set of complex math problems goes far beyond the NP-difficult problems only, because there are problems which are difficult to be solved but do not referred to the NP-difficult class. Thus, the greater information was accumulated on the complexity phenomenon, the less evident it seems to be interpreted in categories of computable functions only.

In 1940s, the era of actual computers has been approached, and attention of researches was shifted to the algorithmic aspects of problem solution. It was agreed that a calculation process for any solvable problem might be represented in the form of an automata with the finite number of states. In other words, if the algorithm of solution of a problem could be represented in the form of automata with the finite number of states, the problem was considered as solvable and simple, otherwise if the

number of states is infinite, the problem was classified as complex.

Whilest such an interpretation of the complexity phenomenon did not provide the answer to the fundamental question on the computation boundary of computing machines, but it was fruitful for the development of the theory of automata, and the latter served as a basis for building J. von Neuman's architecture of sequential computers.

And in turn it had a profound impact on the formation of a new science cybernetics - which was declared by $\mathrm{N}$. Wiener as a universal science on the control and communication in the animal and the machine (Wiener, 1961). The birth of cybernetics has inspired a renewed interest in the anthropological concepts of the complexity phenomenon among researches. In this connection, it is essential to bring to mind the results on this topic given in Ashby's fundamental work (Ashby, 1956), which identified the behavior of any complex artificial system with the brain activity based on adaptation and self-organization.

Historically, some fundamental results concerning the problem of complex objects investigations have been obtained by linguistics and economy scientists. This fact favors Wiener's view that discoveries should be found at the combinations of different sciences.

In 1956, linguist Noam Homski represented his report "Three Models of Language" at the seminar at the Massachusetts Technological Institute, USA. He 
described fundamental concepts of the theory of formal grammars, which had an essential contribution into the problem of building models of abstract automata. As of now, this theory is used for building some software components, for example, such as compiler components.

The mentioned seminar was also remarkable due to other two reports by Alen Newell and Herbert Simon "The Logic Theory Machine" and by George Miller "The Magic Number Seven". Among other things, it followed from the mentioned investigations that computer methods dedicated to the analysis of objects possessed sophisticated behavior should remain the humans behavior, who is trying to solve the problem over learning and refinement of his knowledge on the object under consideration directly during problem solving. In other words, the intelligent system, which is capable of simulating the behavior of a complex object, should possess cognitive functions and operate with semantic categories, say, ontologies. It seems that since this time, two new concepts have been introduced into the computer science - ontology and cognitive analysis.

Ideas of Homski, Newell, Simon and Miller have formed the basis of the modern theory of descriptive logics (Baader et al., 2003), which are used in building modern systems of artificial intelligence.

Economics is another scientific branch, which sheds light on our notions of the complexity phenomenon. It offered a view as to the question on what is an indication of the fact that a complex object operates rationally and the objectives in hand are accomplished. In other words, the case in point is the manner in which one can estimate "the degree of rational behavior" of a complex object (or system). In 1776, Scotch philosopher Adam Smith published his celebrated book "An Inquiry into the Nature and Causes of the Wealth of Nations".

He stated theoretical concepts concerning the problem of economic relations between the people in any economic system. The latter has been considered as a complex system comprised of separate agents, which tended to get maximize incomes.

However, the amount of maximum incomes cannot be a priori estimated. In these circumstances, this brings up the question: What should be adopted as a measure of optimal behavior of each agent (a measure of optimal decision)? In response to this question, A. Smith has brought into use the concept of satisfactory optimal decisions, which mean improvement in the financial state of a separate agent compared to other agents. Thus, instead of finding the best solution (the process which may take a huge time), it is suggested a relative improvement of states of an agent with respect to other agents as a criterion of optimal decision. This concept of behavior optimality of objects of complex systems does not lose its actuality up to the present time. Moreover, this point of view has been formulated in the past by Leon Walras and notably by Frank P. Ramsey (Ramsey, 1931), and also it has formed the basis for von Neuman's and Morgenstern's game theory (von Neumann and Morgenstern, 1944). The crown of the concept of satisfactory optimality belongs to Herbert A. Simon, who published his book in 1947 (Simon, 
1947) and later he got the Nobel Prize in economics in 1978 for his satisfactory theory.

\section{Definition of complex objects and some modern direction of investigations}

A retrospective journey into the history of research of complex objects and systems made above gives grounds to reason that the case in point is phenomenon which is conceptually interdisciplinary, and as a consequence it requires development of specific methodologies and approaches to be studied. Perhaps for this reason the recent history of investigations in this field is associated with the development of mathematical methods of system analysis and information technologies of computer simulation, that is with those which bear up against abstract categories and models. Modern system theory and computer science recognize a number key features of complex objects and systems, and among them are:

- unique behavior,

- weak prediction of future states,

-information non-entropy,

- emergence,

- development through jump-like changes of states

-and some other.

For a detailed discussion of this subject, please, see appropriate literature and Internet sources. Next, we would like to dwell on some specific topics, which (in the author's opinion) are of fundamental importance in the field of computer simulation. One can note at least three major directions in the development of computer facilities dedicated to the research and synthesis of complex information objects and systems, and they are:

- theory of interoperable objects,

- theory of existentional computer platforms, and

- theory of building math and computer models of complex objects, systems, and processes.

The program objects which are realized using different programming languages, operate under control of different operating systems and within different environments, but nevertheless are capable to interact with other similar objects transparently to the user, are called interoperable objects (W. Rogoza, 2006). Metadata and meta-algorithms are usually the constituent parts of any interoperable

object, due to which such objects take intelligent features. Interactions of the interoperable objects can be realized using high-level special-purpose languages of knowledge representation.

The computer platforms, which have soft- and hardware facilities, allowing interoperable objects to interact, are called existentional computer platforms. Frequently the mentioned platforms are implemented with the use of special- 
purpose middleware software. For example, in the case of the well-known CORBA platform, the above functionality is realized by using Object Request Broker middleware (Orfali et al., 1997). There are a number of existentional platforms, which are successfully used in different applications. They are:

- CORBA(Component Request Broker Architecture) mentioned above,

-DCOM (Distributed Component Object Model),

- Java/RMI (Remote Method Invocations with Java),

- Microsoft.NET Platform, the platform of component programming,

-DARPA CoABS(Control of Agent Based Systems),

- GRID platform,

- Cloud-computing platform,

-A4 (Agile Architecture and Autonomous Agents), the environment, which realizes the control over autonomous agents in the GRID platform,

-Condor, the environment which combines personal computers, mainframes, and clusters,

- Legion(the object-oriented programming infrastructure that combines different platforms into the common-used platform using meta-classes paradigm and forms vertical hierarchical structure),

-ACG (Agent-Based Computational Grid, the hybrid platform that combines agent technologies with the GRID and CORBA),

-IGAP (Intelligent Grid-Agent Platform, the hybrid platform based on the use of ontologies),

-and some others.

The theory of building mathematical and computer models now takes a lot of paths, it is substantially more subject-oriented, as opposed to the previous theories of interoperable objects and existentional platforms which are essentially subjectinvariant. Let us dwell on some specific peculiarities of this area of scientific exploration.

A possible definition of math model can be given as follows. The mathematical model of a certain object is said to be an abstraction description (in the form that admits its interpretation as a programming code) of stable and repetitive (immanent) properties, which can be reproduced using the model developed with a certain accuracy at any instant of time within the observation domain.

Strictly speaking, the above definition is inapplicable in the case of complex object models because of the fact that they possess weak predictable behavior (please, see the above definition of a complex object). In such an event, does it make sense a concept of mathematical model as respect to class of complex objects?

To tackle this fundamental question of math simulation of complex objects, we can call our attention to examples of complex objects in interdisciplinary sciences and try to clear up a question, what properties they possess and whether they can be reflected in mathematical models. With this in mind let us consider the class of objects studied in the theory of non-equilibrium thermodynamics and in the theory 
of dissipative systems, which have been developed by llya Prigogine, the director of the Solvay International Institute of Physics and Chemistry, Brussels, Belgium, and the director of the Centrum of Statistical Mechanics and Thermodynamics at the Texas University, Austin, USA. He got the Nobel Prize for the research in the mentioned field in 1977.

The dissipative structures are physical systems formed by transformation of non-equilibrium states by the exchange of energy and information between the system components and the environment. It follows from the theory of dissipative structures that self-organization and adaptation form the basis for the mentioned processes. The theory defines the following key features of a dissipative system: relations;

- dynamic behavior, which can be principally reflected by nonlinear math

-openness, due to which exchange of energy and information is possible;

-specific physical states, which are far from equilibrium points in the state space;

- coherent interactions between the system components.

In spite of the fact that findings of the theory have evidently common scientific significance, the lack of connecting link between the matter and information exchange between the parts of a complex system should be considered as a critical area of the theory. Nevertheless, the findings of investigations into the essence of the complexity phenomenon obtained in the theory of dissipative systems have a fruitful bearing on the development of some scientific divisions in mathematics and theoretical physics, and among them are:

- group theory and tensor analysis,

- differential topology,

- non-equilibrium statistic physics,

- non-equilibrium nonlinear thermodynamics

- and so on.

In this regard more advantageous position holds another scientific area synergetics - which was proclaimed by Hermann Haken as the science that studies self-organization and adaptation as common properties of complex objects and systems of any nature (Haken, 1977; Haken, 1988). Due to this fact, the synergetic theory has filled a significant place in the modern area of system research.

As to the mentioned theory, there are a number of general properties, which possesses each complex object or system, in one form or another. They are as follows.

Property 1. Hierachy. Nature is ordered hierarchically and forms several types of open systems: 1) stable, 2) adaptive, 3) evolving. The relation between them is realized through chaotic, non-equilibrium states located at the neighboring hierarchical levels.

Property 2. Existence of non-equilibrium states. It is a necessary condition for the formation of new structural organizations and functionality. 
Property 3. Emergency. The structures formed possess new functionality that is not a trivial sum of functions of constituents.

Property 4. Self-organization. Complex system is capable of forming new structures that possess new functionalities.

Property 5. Exchange of energy, information, and matter in the non-equilibrium states. The self-organizing systems are always open for information, energy and matter exchange, which are necessary factors of structural ordering. Moreover, in highly non-equilibrium states, complex object and systems are capable of perceiving of external information, energy, and matter, which they do not

perceive in states closed to equilibrium.

Property 6. Corporative behavior. In non-equilibrium states, relative independence of system components gives way to the corporative behavior, when close components are combined together for good agreement of their actions.

Property 7. Bifurcations, points of attraction. In states that are far from equilibrium, bifurcation mechanisms may take place, that is non-equilibrium states may result in the separation of states or formation of attractors.

Just as the theory of dissipative structures has taken significant impact on a number of interdisciplinary scientific areas, the synergetics theory made for the development of a number branches of modern science, such as:

-the dynamic chaos theory and the deterministic chaos theory (for example, the turbulence theory),

-fractal theory,

- phase transition theory,

- linguistic synergetics,

-some sections of the theory of processes of chemical kinetics,

-and so on.

Advances of the theory of dissipative systems, the general system theory, and synergetics have an important bearing on the development of some modern scientific areas, and certain of them even gained a status of the branch of science with its own right, they are:

-the catastrophe theory,

-the theory of solution of ill-conditioned math problems, as they are called,

-the theory of information retrieval,

- the theory of simulated evolution,

-the theory of soft-computing, and in particular the theory of building selforganized simulating systems, etc.

The spectral catastrophe theory is aimed at promoting a better understanding and formalization of the bifurcation phenomena (please, see property 7 of complex systems proclaimed in the synergetics). Vladimir Arnold (Thom, 1952; Arnold and Afraimowich, 1999), the developers of the theory, have suggested math means allowing discontinuous functions of continuous arguments to be described by math means. The results obtained in the theory are of fundamental importance in 
simulation and prediction of social, ecological, and economic phenomena, and are widely used today

in appropriate science areas.

A lot of the credit in problems of solution of ill-conditioned math problems must go to Russian academician A.Tikhonov and his students (see, for example, (Tikhonov, 1963)). Interesting results concerning the use of artificial neuron networks with radial basic functions in the solution of ill-conditioned problems have been obtained by D. Phillips (Phillips, 1962). The mentioned investigations cover the fields of the complex object area, noted above as properties 2 and 7 of synergetic systems. The findings of the mentioned investigations are used in the image recognition, artificial neuron networks based on the self-learning paradigm and so on.

Another scientific area, which has a direct relation to computer science is information retrieval (Manning et al., 2008), which has assumed a great significance in the development of intelligent data mining systems, say, semantic Web.

The "simulated evolution" term has been proposed in (Fogel et al., 1966), and then it was enriched by different authors with a number of practically useful methods. The simulated evolution is developing now into three basic directions: genetic algorithms, evolution strategies, and evolution programming (Rutkowska et al., 1999). In the mentioned works attention was drawn to the fact that

such properties of complex objects and systems as non-entropy and weak predictability of future states would be naturally reflected in models synthesized using evolution and adaptation principles. The "soft computing" term owes its origin to works of L.A. Zadeh(see, for example, Zadeh, 1973), and a variety of methods, which fall into this category of simulation methods, denotes that this approach require attention.

\section{Conclusion}

We can see, that the presented properties of complex systems obtained in biology, in the theory of dissipative structures, synergetics, and in the general system theory are principally closed and they complement each other. This gives confidence to the certainty of general properties of complex objects and systems declared in those scientific areas. But every time, when we deal with declarative

statements, the question arises of whether the statements have practical significance, and in particular in the area of information technologies?

If this question would be asked, say, at 1930s, the response probably could be negative, because, as was noted above, at the dawn of the age of computer science, researchers have assumed that there were some algebraic measures of complexity, and any problem would be solvable using universal computing machines. However, the way toward deeper insight into understanding of complexity phenomenon was found to be substantially more difficult and knotty. At the present time, a number of statements related to the topic discussed we can find in numerous realizations of various information technologies and intelligent systems. For example, hierarchy (in the form of inheritance of classes) is one of the 
basic principle of the objective programming paradigm. Evolution simulation forms the basis of genetic algorithms in the artificial intelligence. Different forms of emergency and

self-organization we can find in implementations of artificial neuron networks. Corporate behavior is used in the Hebb's theory of self-learning in artificial intelligence. Ontologies now are used as the basis for the semantic Web-networks.

As can be seen from the given overview of the area of complex system research, the science of biology, the general system theory, the theory of dissipative systems as well as the synergetics have drawn to the same conclusion on the necessity of further developing information theory of self-organization and adaptation of complex objects and systems.

Much has been learned in the past 50-70 years, but nevertheless it would be suggested that we are at the beginning of a long path, on which one would expect surprising discoveries ahead of us in this area of information technology.

\section{References}

1. Arnold, V. I. and Afraimowich, V. S. Bifurcation Theory and Catastrophe Theory, Springer, 1999.

2. Ashby, W. R. An Introduction to Cybernetics, Chapman \& Hall, Ltd., London, 1956.

3. Ashby,W. R. Design for a Brain. The Origin of adaptive Behaviour, Chapman \& Hall, Ltd., London, 1960.

4. Baader, F., McGuinness, D. C. D. L., Nardi, D. and Pater-Schneider, P. F. The Description Logic Handbook. Theory, Implementation, and Application, Cambridge University Press, Cambridge, 2003.

5. Cobham, A. The intrinsic computational difficulty of functions, Proceedings of the 1964 International

6. Congress for Logic, Methodology, and Philosophy of Science, 1964, Jerusalem, Elsevier/North-Holland, pp. 24-30.

7. Cook, S. A. The complexity of theorem-proving procedures, Proceedings of the 3th Annual ACM Symposium on Theory of Computing, ACM 1971, New York, ACM Press, pp. 151-158, 1971.

8. Edmonds, J. Paths, trees, and flowers, Canadian Journal of Mathematics (17): 449467, 1965.

9. Fogel, L. J., Owens, A. J. and Walsh, M. J. Artificial Intelligence through Simulated Evolution, Wiley, New York, 1966.

10. Gödel, K. Über formal unentscheidbaresätze der principia mathematica und verwandtersysteme, Monatshefterf "urMathematik und Physik (38): 173-198, 1931.

11. Haken, H. (1977). Synergetics. An Introduction, Springer. Haken, H. Information and Self-Organization. A Macroscopic Approach to Complex Systems, Springer-Verlag, 1988.

12. Holland, J. H. Adaptation in Natural and Artificial Systems, A Bradford Book/The MIT Press, 1992.

13. Hopcroft, J. E., Motwani, R. and Ullman, J. D. Introduction to Automata Theory, Languages, and Computation, Addison-Wesley Publ. Co., Inc., 2001.

14. Karp, R. M. Reducibility among combinatorial problems, in R. E. Miller and J. W. Thatcher (Eds), Complexity of Computer Computations, Plenum, New York, pp. 85-103, 1971.

15. Manning, C. D., Raghavan, P. and Schutze, H. Introduction to Information Retrieval, Cambridge University Press, 2008.

16. Orfali, R., Harkey, D. and Edwards, J. Instant CORBA, John Wiley \& Sons, Inc. Phillips, D. (1962). A technique for the numerical solution of certain integral equations of the first kind, Journal of Association for Computing Machinery 9: 84-97, 1997. 
Серія: інформатика, обчислювальна техніка та кібернетика

17. Ramsey, F. P. Truth and probability, in R. B. Braithwaite (Ed.), The Foundations of Mathematics and Other Logical Essays, Harcourt Brace Jovanovich, New York, 1931.

18. Rogoza, W. Metody i 'srodki projektowania obiekt'ow interoperabilnych, Akademicka Oficyna Wydawnicza EXIT, Warszawa, 2006.

19. Russel, S. J. and Norvig, P. Artificial Intelligence. A Modern Approach, Prentice-Hall, Upper Saddle River, New Jersey, 2003.

20. Rutkowska, D., Piliński, M. and Rutkowski, L. (1999). Sieci neuronowe, algorytmy genetyczne i systemy rozmyte, PWN, Warszawa, 1999.

21. Simon, H. A. Administrative behavior, Macmillan, New York, 1947.

22. Thom, R. Espaces fibrés en sphéres et carrés de steenrod, Annales Scientifiques de l'Ecole Normale Supérieure 69(3): 109-182, 1952..

23. Tikhonov, A. N. On solving incorrectly posed problems and method of regularization, Doklady Akademii Nauk USSR 151: 501-504, 1963.

24. von Neumann, J. and Morgenstern, O. The Theory of Games and Economic Behavior, Princeton University Press, New Jersy, 1944.

25. Wiener, N. Cybernetics, or Control and Communication in the Animal and the Machine, The Technology Press and JohnWiley \& Sons, Inc., New York Hermann et Cie, Paris, 1948.

26. Wiener, N. Cybernetics, or Control and Communication in the Animal and the Machine. 2nd ed., The M.I.T. Press and John Wiley \& Sons, Inc., New York, London, 1961.

27. Zadeh, L. Outline of a new approach to the analysis of complex systems and decision processes, IEEE Transactions on Systems, Man and Cybernetics SMC-3: 28-44, 1973. 